\section{COMPARISON OF CARBON DYNAMICS IN TROPICAL AND TEMPERATE SOILS USING RADIOCARBON MEASUREMENTS}

\author{
Susan E. Trumbore ${ }^{1}$ \\ Center for Accelerator Mass Spectrometry \\ Lawrence Livermore National Laboratory \\ Livermore, California
}

estimated annual flux of carbon into and out of this soil is 0.22 to $0.45 \mathrm{kgC} \mathrm{m}^{-2} \mathrm{yr}^{-1}$. Rapid turnover of organic matter with density $<1.6-2.0 \mathrm{~g} \mathrm{~cm}^{-3}$ contributes a major component of the annual flux of carbon into and out of both soil types. Hydrolysis of mineral soil organic matter of density $>1.6-2.0 \mathrm{~g}$ $\mathrm{cm}^{-3}$ removed ${ }^{14} \mathrm{C}$-enriched components from the temperate soil but had no effect on the ${ }^{14} \mathrm{C}$ content of the residue in $0-22 \mathrm{~cm}$ layer of the tropical soil. The results presented here show that carbon cycle models which treat soil carbon dynamics as a single reservoir with a turnover rate based on radiocarbon measurements of bulk soil organic matter underestimate the annual fluxes of organic matter through the soil organic matter pool, particularly in tropical regions.

\section{INTRODUCTION}

\section{Role of Soils in the Global Carbon Budget}

Recent debate over the importance of soil organic matter in the global carbon budget [Tans et al., 1990; Schlesinger, 1990, Prentice and Fung, 1990; Jenkinson et al., 1991] has emphasized a lack of fundamental knowledge of soil carbon dynamics. An understanding of the degree and timing of the response of this carbon reservoir to perturbations associated with climatic or land use change requires knowledge of both the inventory of carbon in soils and the turnover rate of carbon in soil organic matter. An estimated 1300 to $1500 \mathrm{GtC}(1 \mathrm{GtC}=$ $10^{15} \mathrm{gC}$ ) is stored globally as organic matter in the upper meter of mineral soils [Schlesinger, 1977; Post et al., 1982]. This is roughly twice the
Paper number 93GB00468.

0886-6236/93/93GB-00468 $\$ 10.00$
Copyright 1993

by the American Geophysical Union.

${ }^{1}$ Now at Department of Geosciences, University of California, Irvine, CA 92717-3100.

$0886-6236 / 93 / 93$ GB-00468 $\$ 10.00$


estimated storage of carbon either in the atmosphere or in the living biosphere (both approximately 700 GtC [Atjay et al, 1979]), and 300 times the annual fossil fuel input [Intergovernmental Panel on Climate Change, 1990]. Little information is available from which to determine the residence time of carbon in the soil organic matter reservoir, especially regarding its variation with soil forming factors such as climate, topography, time, parent material, and land use. In large part, the lack of knowledge is due to the complex, heterogeneous nature of soil organic matter (see reviews in the works by Stevenson [1982] and Stevenson and Elliott [1990]). Soil organic matter includes a wide spectrum of organic compounds, from labile components, such as relatively fresh vascular plant material and microbial biomass, to refractory components which accumulate slowly over thousands of years.

In order to understand the role of the soil carbon pool in the global carbon cycle, it is necessary to quantify the accumulation, transformation, translocation, and eventual decomposition of soil organic matter on time scales ranging from seasonal to millennial. Models of soil carbon turnover at the ecosystem level [Jenkinson and Raynor, 1977; Parton et al., 1987; Emanuel et al., 1985; Van Bremen and Feijtel, 1990; Jenkinson et al., 1991], differentiate soil organic carbon into fast (annual turnover), slow (decadal to centennial turnover) and passive (millennial and longer turnover) pools. As these models have been successful in explaining soil carbon dynamics in the ecosystems for which they have been developed, a method with which to determine the distribution of soil organic carbon among these pools in a variety of ecosystems and soil types is greatly needed.

\section{Quantification of Soil Carbon Pools Using ${ }^{14} \mathrm{C}$}

Carbon 14, the radioactive isotope of carbon, is a useful tool for deciphering the dynamics of carbon cycling in soils [Stout et al., 1981; Balesdent, 1987; Scharpenseel et al., 1968a, b, 1989; Trumbore et al., 1989]. New carbon is added to soils as vascular plant material, with a ${ }^{14} \mathrm{C} /{ }^{12} \mathrm{C}$ ratio close to that of contemporary (that year's) atmospheric $\mathrm{CO}_{2}$. The degree to which the ${ }^{14} \mathrm{C} /{ }^{12} \mathrm{C}$ ratio in soil organic matter differs from the vascular plant matter from which it is derived reflects the mean age of carbon in soils, often used to calculate a Mean Residence Time (MRT) [Paul et al., 1964]. Several problems exist, however, with using only the ${ }^{14} \mathrm{C}$-derived MRT of bulk soil organic matter to interpret soil carbon dynamics. First, the presence of unknown quantities of bomb ${ }^{14} \mathrm{C}$ in soils sampled since the mid-1960s will cause the MRT to be underestimated in modern soils. Even where archived soils (sampled prior to 1960) are available, variations in the prebomb atmospheric ${ }^{14} \mathrm{C}$ content, combined with the analytic-al uncertainty of the ${ }^{14} \mathrm{C}$ measurement, limit the use-fullness of radiocarbon to study carbon pools with MRT less than several hundred years. Second, the ${ }^{14} \mathrm{C}$ MRT cannot be used to directly determine the total flux of $\mathrm{CO}_{2}$ to the atmosphere from soil organic matter. The calculation of $\mathrm{CO}_{2}$ fluxes directly from the ${ }^{14} \mathrm{C}$ MRT ignores other loss mechanisms, such as the transport of dissolved or particulate organic matter out of the soil profile. These processes may be the ultimate factor defining long-term residence time of carbon in refractory organic matter components [Van Bremen and Feijtel, 1990]. Finally, the MRT based on the ${ }^{14} \mathrm{C}$ age is a misleading measure of the annual fluxes of carbon into and out of soil organic matter. This results primarily from the fact that the average age of a carbon atom in soil organic matter, a reservoir made up of a suite of components with very different residence times, does not necessarily equal the average time spent by a carbon atom in soil organic matter (the turnover time [Balesdent, 1987]). For example, a ${ }^{14} \mathrm{C}$ age of 1000 years obtained for bulk soil organic carbon cannot distinguish between the homogeneous case, in which all of the carbon in the soil has a turnover time of 1000 years, and the inhomogeneous case, in which $75 \%$ of the organic carbon has a turnover time of 20 years, and $25 \%$ a turnover time of 5000 years. Although these two soils would have the same MRT based on bulk ${ }^{14} \mathrm{C}$ content, the annual flux of carbon into and out of the soil, and the response of soil carbon to a perturbation, will differ greatly between these two cases.

Two approaches have been developed to use ${ }^{14} \mathrm{C}$ data to break soil organic matter down into more labile and more refractory constituents. The first method uses ${ }^{14} \mathrm{C}$ measurements of operationally defined fractions to partition soil organic matter into constituent labile and refractory pools [Paul et al., 1964; Campbell et al., 1967; Martel and Paul, 1974; Goh et al., 1976, 1977, 1984; Scharpenseel et al., 1968a, b, 1984; Trumbore et al., 1989, 1990]. The second method is based on the observed incorporation of bomb-produced radiocarbon into soil organic matter during the 30 years since the end of atmospheric weapons testing [Anderson and Paul, 1984; O'Brien and Stout, 1978; O'Brien, 1984, 1986; Harkness et al., 1986; Trumbore et al., 1989, 1990; Jenkinson et al., 1992]. This approach requires ${ }^{14} \mathrm{C}$ measurements of soil organic matter sampled prior to 1960 for comparison with contemporary samples. A large increase in ${ }^{14} \mathrm{C}$ content over the past 30 years indicates that significant portions of the soil organic matter are exchanging carbon with atmospheric $\mathrm{CO}_{2}$ on decadal and shorter timescales. A comparison of ${ }^{14} \mathrm{C}$ in prebomb and postbomb soils also provides the best means to test the usefulness of various operationally defined separation procedures.

Measurement of ${ }^{14} \mathrm{C}$ by accelerator mass spectrometry (AMS) has greatly reduced the 
difficulties previously involved in studies of ${ }^{14} \mathrm{C}$ in soil organic matter. Archived soil samples are generally so small that they do not contain enough carbon to measure ${ }^{14} \mathrm{C}$ by decay counting methods. Using AMS, measurement of ${ }^{14} \mathrm{C}$ in several fractions of soil organic matter may be made using only several hundred milligrams of soil. An additional advantage of AMS is the high rate of sample throughput. Up to 100 samples may now be measured in a 24-hour period using AMS [Davis et al., 1990]. The same number of measurements would require several months to a year in many counting laboratories.

\section{SAMPLES}

A comparison of the organic carbon dynamics in litter and soils from the western Sierra Nevada and tropical regions (Costa Rica and Columbia) was published by the late Hans Jenny [Jenny et al., 1949; Jenny, 1950]. He observed that, although overall input and decomposition rates of fresh plant material are higher in the warm, humid tropics, tropical soils contain more carbon than the Sierra soils. The ratio of carbon in detrital layers to that in the mineral soil is much smaller in tropical systems than in temperate systems [Jenny, 1950], indicating large differences in the way carbon cycles in these soil systems. Given the large probable difference in soil carbon dynamics between these two soil types, comparisons of the radiocarbon content of organic matter in prebomb and postbomb soil pairs were made in this study for environments similar to those studied by Jenny: moist tropical forest (Amazon Basin, Brazil) and dry temperate forest (western slope of the Sierra Nevada mountains in central California). Information on the locations, climate and vegetation characteristics of these sites are summarized in Table 1. More specific information on soil chemical and physical properties are presented together with ${ }^{14} \mathrm{C}$ data in Table 2.

\section{Temperate Soil, California}

Samples of a soil named the Musick Sandy Loam, described and collected in 1959, were obtained from the archives at the U. S. National Soil Survey Investigations Laboratory. This soil is classified as an Ultisol (Xerult), signifying a soil developed in Mediterranean climate, with an argillic horizon (moderate clay contents), low base saturation and red to yellow color signifying the presence of iron and aluminum hydroxides [Brady, 1984]. A detailed profile description may be found in Soil Survey Investigations Report 24 (California). The sampling site was located on the western slope of the Sierra Nevada mountains, Amador County, California, at an elevation of approximately $1300 \mathrm{~m}$. The vegetation at this elevation consists primarily of oak and pine, with grasses and shrubs (see Table 1). A contemporary soil profile was collected in 1990 , approximately $2 \mathrm{~m}$ from the location of the original soil pit (as located by the land owner). Some disturbance of the site vegetation had occurred

TABLE 1. Summary of general characteristics for the tropical and temperate soils used in this study.

\begin{tabular}{|c|c|c|c|c|c|}
\hline $\begin{array}{l}\text { Soil/ } \\
\text { Life Zone }\end{array}$ & $\begin{array}{c}\text { Climate } \\
\text { Temp., Precip. }\end{array}$ & $\begin{array}{l}\text { Parent } \\
\text { material }\end{array}$ & $\begin{array}{l}\text { Vegetation } \\
\text { present }\end{array}$ & $\begin{array}{c}\mathrm{NPP} \\
\mathrm{kgC} \mathrm{m}^{-2} \mathrm{yr}^{-1}\end{array}$ & $\begin{array}{c}\text { Soil C } \\
\mathrm{kgC} \mathrm{m}^{-3}\end{array}$ \\
\hline $\begin{array}{l}\text { Oxisol (Kaolinitic Yellow Latosol) } \\
\text { Moist Tropical Forest }\end{array}$ & $\begin{array}{c}22 \text { to } 26^{\circ} \mathrm{C} \\
>200 \mathrm{~cm} \mathrm{yr}^{-1}\end{array}$ & sediments* & $\begin{array}{l}\text { terra firme } \\
\text { tropical forest }\end{array}$ & 1.0 & 11.4 \\
\hline $\begin{array}{l}\text { Ultisol (Musick) } \\
\text { Dry Temperate Forest/Scrub }\end{array}$ & $\begin{array}{c}-5 \text { to } 20^{\circ} \mathrm{C}^{-1} \\
20-30 \mathrm{~cm} \mathrm{yr}^{-1}\end{array}$ & $\begin{array}{r}\text { granodiorite } \\
\text { li }\end{array}$ & $\begin{array}{l}\text { ponderosa pine, } \\
\text { e oak, blue wild }\end{array}$ & $\begin{array}{l}0.3-0.5 \\
\text { rye }\end{array}$ & $7: 1$ \\
\hline
\end{tabular}

\begin{tabular}{llcl} 
Soil ID & \multicolumn{1}{c}{ Location } & Year Sampled & Relevent References \\
\hline Oxisol 1 & Curua-Una, Brazil & 1959 & $303 ;$ profile 24 [Sombroeck, 1966, p. 129] \\
Oxisol 2 & Belem, Brazil & 1959 & 300; profile 25 [Sombroeck, 1966, p. 130] \\
Oxisol 3 & Manaus, Brazil & $1978 ; 1986$ & Leenheer, 1980; Trumbore et al., 1990 \\
Ultisol 1, 2 & Amador County, & 1959,1992 & SSIR No. 24 (S59-3-13) [Jenny et al., 1949] \\
\hline
\end{tabular}

More specific information and soil decsriptions may be found in the references. Data on NPP and soil carbon storage for these ecosystem types are taken from the literature [Atjay et al, 1985; Post et. al, 1982].

* there is some debate as to to whether soils in the Amazon Basin are developed on fluival sediments

(Sombroeck, 1966) or represent very thick primary weathering sequences (Irion, 1984). 


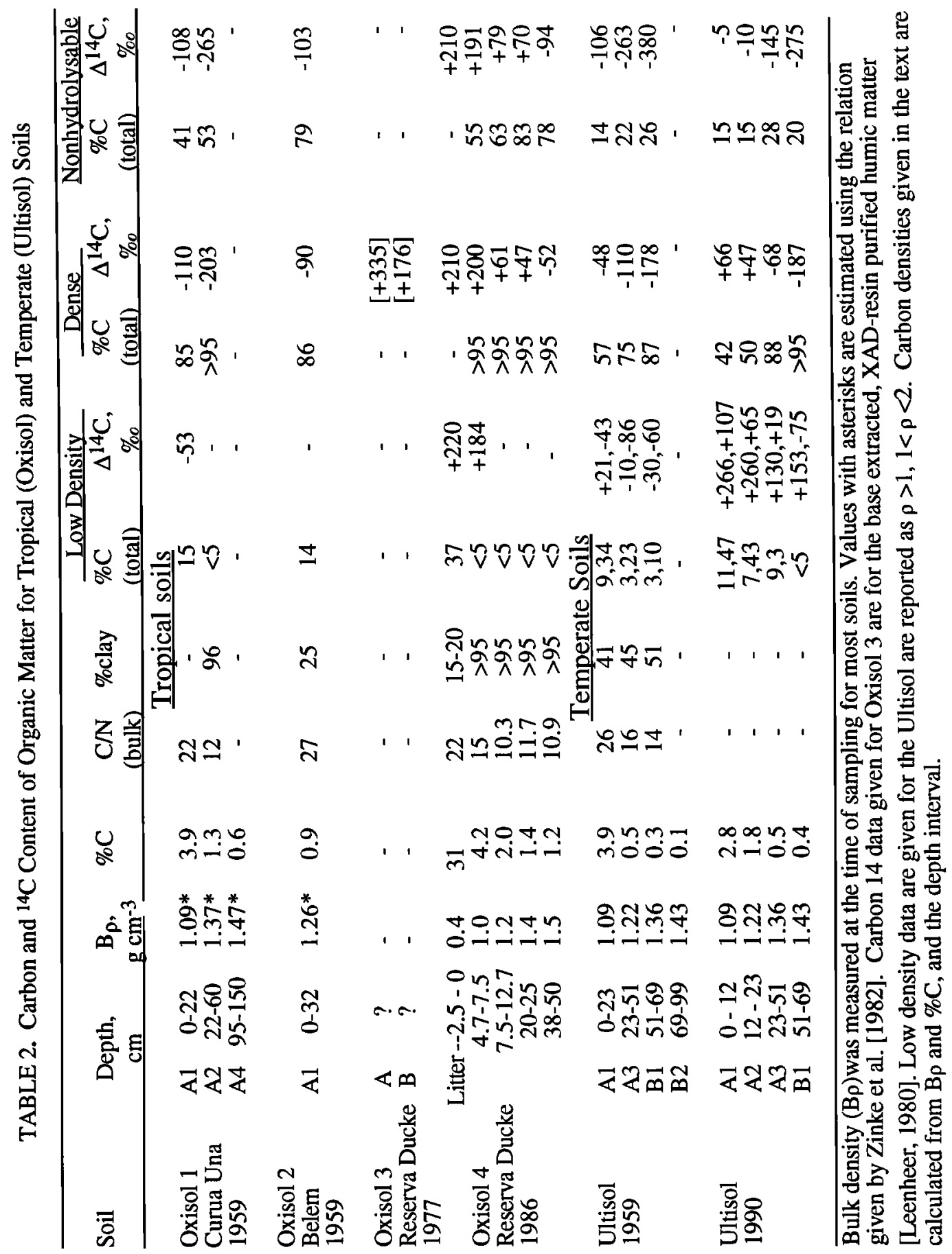


during the 30 years between sample collections. In the 1950 s the understory in this area was burned regularly to eliminate underbrush. Burning was discontinued in the late 1950s, and manzanita scrub grew up in the area. The scrub was cut back in the late 1980 s.

\section{Tropical Forest Soils, Amazon Basin, Brazil}

Samples from two tropical forest soil profiles, collected in Brazil in 1959, were obtained from W. Sombroeck (then Director, International Soil Resource and Information Center, Wageningen, the Netherlands). The profiles from which the samples were taken are described by Sombroeck [1966, profiles 303 and 300]. Both soils are described as Oxisols (Orthod), signifying a wet, warm, climate, and a high degree of weathering [Brady, 1984]. These soils have high clay contents (predominantly kaolinite), mixed with abundant iron and aluminum hydroxides. The first of the archived tropical soil samples (Sombroeck profile 303) were collected in Curua Una, Brazil, near the center of the Amazon Basin. Two samples from this profile were available, integrating $0-22 \mathrm{~cm}$ and $22-60 \mathrm{~cm}$ depths. The second archived Oxisol profile (Sombroeck number 300) was collected near Belem, Brazil, close to the mouth of the Amazon River. Only the 0-32 $\mathrm{cm}$ layer from this soil was available. It has much lower clay contents than the Curua Una soil (Table 2).

The contemporary tropical soil profile was collected in 1986 from the Reserva Ducke, about $17 \mathrm{~km}$ northeast of Manaus, Brazil, and the site of the ABLE IIa and IIb experiments [Harriss et al., 1990]. In addition, two samples of humic matter, extracted from a soil in the Reserva Ducke in 1978, were obtained from J. Leenheer (U.S. Geological Survey; described by Leenheer [1980]). Soils in the Reserva Ducke sampled for this study were also described as Oxisols, with clay contents similar to the Curua Una soil.

All three of the tropical soils obtained for this study are thought to be developed on fluvial clay deposits of Pliocene or Pleistocene age [Sombroeck, 1966], although it has also been suggested [Irion, 1984] that the soils from this region may represent in situ weathering profiles. Vegetation at all sites is terra firme (not seasonally flooded) tropical forest. Nonetheless, the three Oxisols obtained for this study cannot be considered directly comparable. Sombroeck's profile 303 (from Curua Una) will be used to provide one limit with which to compare the 1978 and 1986 Reserva Ducke soils. The justification for this comparison is seen in the comparable carbon and clay contents of the two soils, and in the similarity in pre-bomb ${ }^{14} \mathrm{C}$ contents measured in the two archived Oxisols (see Table 2), despite their differences in location and particle size. As far as it was possible to ascertain, all of the tropical sites were undisturbed primary forest at the time of sampling.

\section{METHODS}

All archived soils were stored dry, and had been sieved to remove components $>2 \mathrm{~mm}$, including large root fragments. Contemporary soil samples collected for this study were sieved to remove components $>2 \mathrm{~mm}$, and either oven-dried or stored in a refrigerator prior to analysis.

Fractionation of the soil organic matter followed the method described by Trumbore et al. [1989] and is illustrated in Figure 1. Initial acidification to remove calcium carbonate (not present in any of the four profiles) was followed by a density separation [Sollins et al., 1983] to quantitatively remove vascular plant debris, charcoal and easily soluble organic matter. A zinc bromide solution with density of $1.6 \mathrm{~g} \mathrm{~cm}^{-3}$ was used for the tropical soil. The temperate soil, collected and analyzed 2 years after the tropical soil, was fractionated using a new product, sodium polytungstate (density of $2.0 \mathrm{~g} \mathrm{~cm}^{-}$ ${ }^{3}$ ). Sodium polytungstate is preferable because it is inert (not poisonous or corrosive), and may be used to attain liquids of density greater than $2.0 \mathrm{~g} \mathrm{~cm}^{-3}$. Both heavy liquids solubilize some (small) portion of the soil organic matter, which is not quantified in the procedure. Three to six grams of dried soil were shaken vigorously with the dense solution in a 25 $\mathrm{mL}$ centrifuge tube. The mixture was centrifuged,

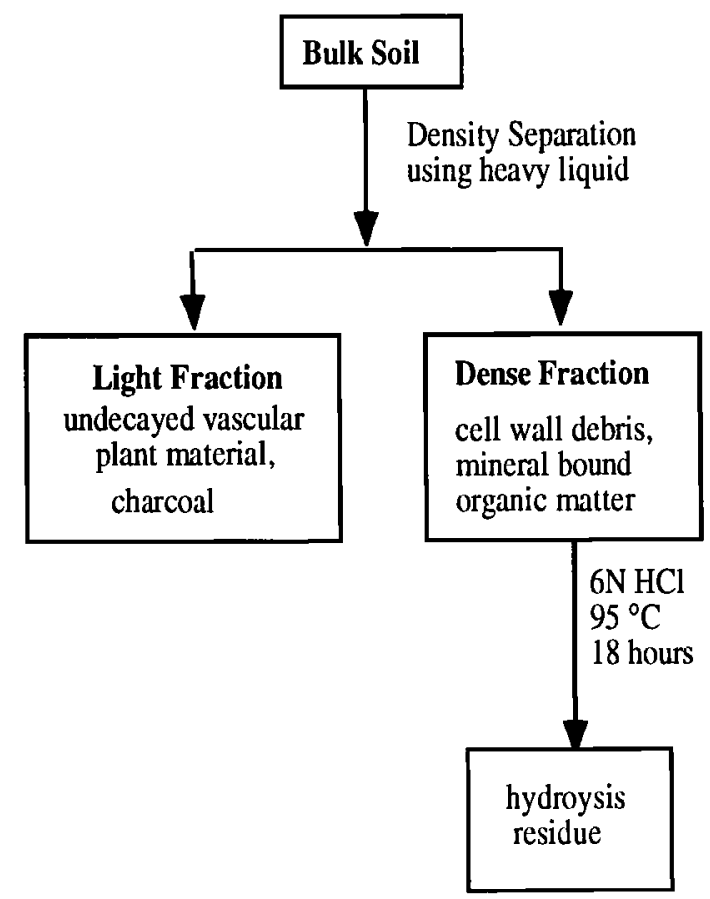

Fig. 1. Fractionation scheme used for soil organic matter, as described in the text. 
and the supernate filtered to remove floating lowdensity material. The filtered solution was reused to exhaustively extract remaining low density material (3-6 resuspension-centrifugation cycles were required in near-surface layers). The denser residue, including organic matter stabilized by sorption to mineral surfaces and microbial cell wall debris [Spycher et al., 1983], was rinsed three times with distilled water by resuspension/centrifugation, vacuum dried, and ground. This fraction, hereafter referred to as the dense fraction, was the substrate for further fractionation.

Acid extraction involved hydrolysis of the soil in $6 \mathrm{~N} \mathrm{HCl}$ for 18 hours at $95^{\circ} \mathrm{C}$. The soil was then centrifuged, and the hydrolyzate separated. The residue was rinsed three times with distilled water, then vacuum dried.

The tropical soil samples from Reserva Ducke obtained by Leenheer [1980] represent the organic matter extracted by base $(\mathrm{NaOH})$, and subsequently purified using XAD-8 resin [Leenheer, 1980]. Comparisons of base and acid extracted organic carbon from the upper $20 \mathrm{~cm}$ layers of the prebomb tropical soil samples [Trumbore et al., 1990] showed no difference in ${ }^{14} \mathrm{C}$ content between unextracted, base extracted and acid extracted soil in upper mineral soil layers $(0-22$ or $0-32 \mathrm{~cm}$ depth interval). With increasing depth in the mineral soil, the base extracted material contains increasingly more ${ }^{14} \mathrm{C}$ than the residue [Trumbore et al., 1990; also unpublished data, 1992]. Therefore the ${ }^{14} \mathrm{C}$ content of the extracts obtained from Leenheer may be greater than or equal to the unextracted dense fraction organic matter to which they are compared in this paper.

Samples for ${ }^{14} \mathrm{C}$ analysis were combusted $\left(900^{\circ} \mathrm{C}\right.$ for one hour) with $\mathrm{CuO}$ wire in sealed, evacuated quartz tubes [Buchanan and Corcoran, 1959]. The evolved $\mathrm{CO}_{2}$ was cryogenically purified and manometrically measured to determine the weight $\% \mathrm{C}$ in each fraction. Comparison of $\% \mathrm{C}$ data obtained by sealed tube combustion with those obtained using a commercial $\mathrm{CN}$ analyzer showed good agreement between the two methods. For some of the archived profiles, previously determined $\% \mathrm{C}$ data were available (see references in Table 1). Although agreement between \% C values obtained in this study with these previous results was generally good, some discrepancies exist. The most likely cause for the differences lie in the use of different methods for determining \%C [Jenny, 1950]. The $\% \mathrm{C}$ was converted to a carbon inventory using bulk density data obtained during profile collection, or estimated using equations by Zinke et al [1984]. Errors due to the problems with discrepancies in \%C and estimation of bulk density are large and difficult to estimate, but, in general, where soil bulk density is known and $\% \mathrm{C}$ determinations agree with previous determinations, are estimated at $10-20 \%$ of the total reported soil carbon content. Table 2 shows the values of \%C and bulk density used for the calculation of soil carbon density.

$\mathrm{CO}_{2}$ evolved from high-temperature sealed tube combustion was catalytically reduced to graphite AMS targets using the method of Vogel et al. [1987]. Carbon 14 AMS measurements were made at the PSI/ETH facility in Zuirich, Switzerland [Suter et al, 1984], and at the Center for Accelerator Mass Spectrometry at Lawrence Livermore National Laboratory [Davis et al., 1990]. $\delta^{13} \mathrm{C}$ corrections to ${ }^{14} \mathrm{C}$ data were made using measured ${ }^{13} \mathrm{C} /{ }^{12} \mathrm{C}$ in Zürich; for CAMS determinations $\delta^{13} \mathrm{C}$ were assumed to be $-25 \%$. The error in ${ }^{14} \mathrm{C}$ is less than $1.5 \%$ of Modern for all samples. The source of error from isotopic measurements is always small in comparison with the error involved in calculating the carbon inventory in the soil. Carbon 14 data are expressed as $\Delta^{14} \mathrm{C}$, the deviation, in parts per thousand of the ${ }^{14} \mathrm{C} / 12 \mathrm{C}$ ratio in the sample from that of an absolute standard (oxalic acid decay corrected to 1950 [Stuiver and Polach, 1977]):

$\Delta{ }^{14 C}=\left(\frac{\frac{14 C}{12 C_{\text {sam }}}}{\frac{14 C}{12 C_{\text {std }}}}-1\right) * 1000$

Measurement of the activity of ${ }^{137} \mathrm{Cs}$ in soil samples were made by gamma counting of bulk soil samples. Cesium 137, an isotope produced by atmospheric weapons testing, has a half life of 30 years. In soils, it is primarily associated with clay minerals and organic matter [Monaghan, 1984; Graustein and Turekian, 1986; Dörr and Münnich, 1989]. Comparison of ${ }^{137} \mathrm{Cs}$ with the vertical distribution of bomb-produced ${ }^{14} \mathrm{C}$ yields information about the processes transporting carbon vertically in the soil profile [Dörr and Münnich, 1989; Trumbore et al., 1989].

\section{RESULTS}

\section{Density Fractionation of Soil Organic Matter}

Figure 2 (a through $\mathrm{f}$ ) plots the carbon density and ${ }^{14} \mathrm{C}$ content of organic matter in the temperate soil (Sierra Nevada Ultisol) with depth. The results are separated into components of different density: $<1.0$ $\mathrm{g} \mathrm{cm}^{-3}, 1.0$ to $2.0 \mathrm{~g} \mathrm{~cm}^{-3}$, and $>2.0 \mathrm{~g} \mathrm{~cm}^{-3}$. The low-density fractions $\left(<2.0 \mathrm{~g} \mathrm{~cm}^{-3}\right)$ constitute roughly $50 \%$ of the total soil carbon in the $0-23 \mathrm{~cm}$ layer (Figures $2 \mathrm{a}$ and $2 \mathrm{~b}$; Table 2 ). The ${ }^{14} \mathrm{C}$ content of the nearly unaltered vascular plant material which passes through a $2-\mathrm{mm}$ sieve, $\left(<1.0 \mathrm{~g} / \mathrm{cm}^{3}\right.$; Figure 2d) has $\Delta^{14} \mathrm{C}$ close to atmospheric values at the time of sampling for the $19590-23 \mathrm{~cm}$ layer. The 1990 value of $+270 \%$ for the $<1.0 \mathrm{~g} \mathrm{~cm}^{-3}$ fraction is greater than 1990 atmospheric ${ }^{14} \mathrm{CO}_{2}$ values $(+172$ 

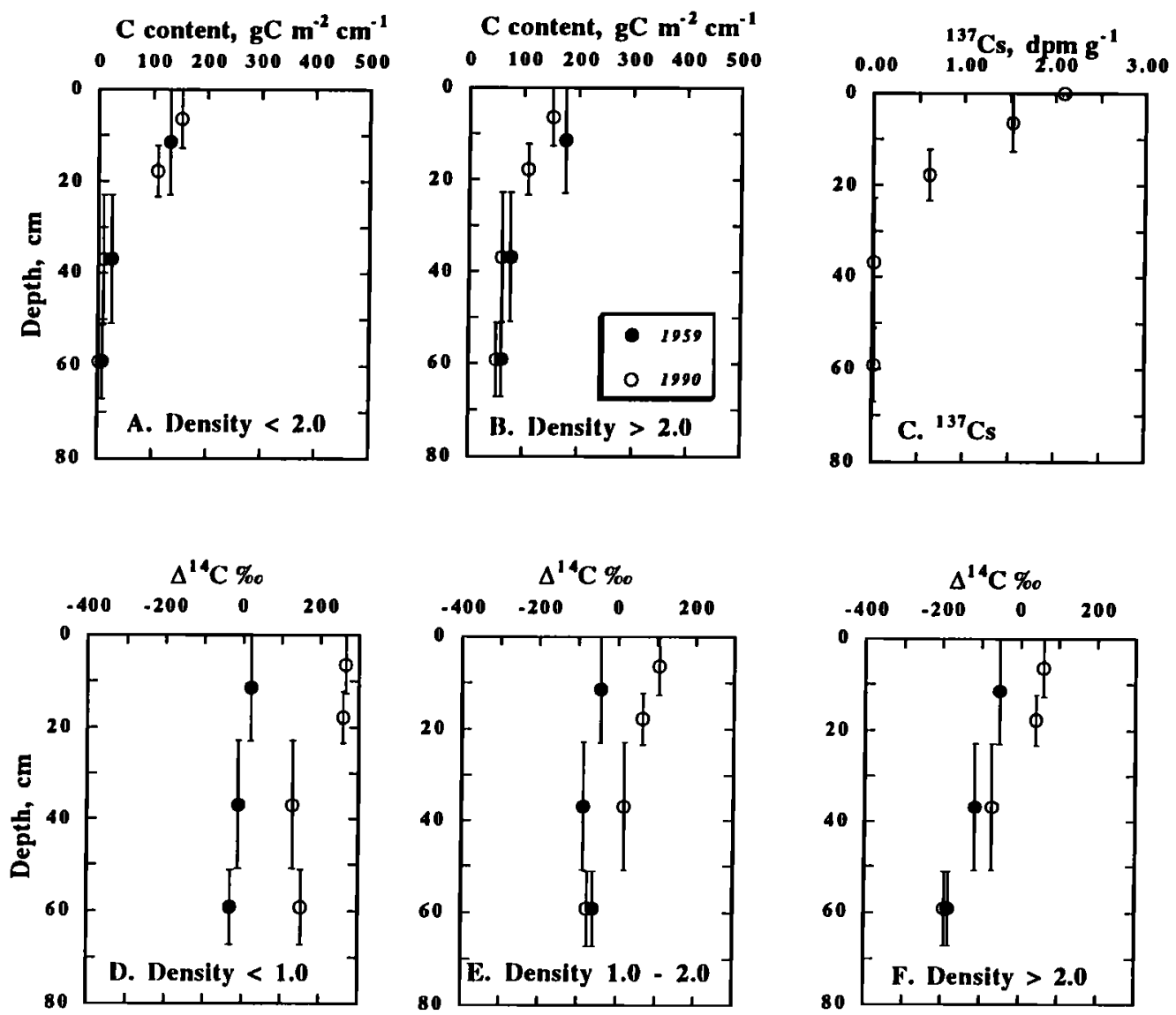

Fig. 2. Results of density fractionation for the Ultisol, Sierra Nevada, California. Carbon inventory (in $\mathrm{gC} \mathrm{m}^{-2}$ per $\mathrm{cm}$ depth) and ${ }^{14} \mathrm{C}\left({ }^{14} \mathrm{C}, \%\right.$ o $)$ content are plotted versus depth (in centimeters). The points represent the midpoint of the interval represented by each sample; the "error bars" define the vertical extent of each layer. Archived samples (1959) are shown as filled circles; contemporary samples (1990) as open circles. The figures show carbon contained in the fraction with density (a) less than and (b) greater than $2.0 \mathrm{~g} \mathrm{~cm}^{-3}$, and (c) ${ }^{137} \mathrm{Cs}$ content of the bulk soil. Carbon 14 contents of three density fractions are shown: density (d) $<1.0 \mathrm{~g} \mathrm{~cm}^{-3}$; (e) between 1.0 and $2.0 \mathrm{~g} \mathrm{~cm}^{-3}$; and $(\mathrm{f})>2.0 \mathrm{~g} \mathrm{~cm}^{-3}$ (the "dense" fraction).

$\pm 10 \%$ [Aravena et al., 1992]). These data may be explained if the combined residence time of lowdensity carbon in plants and in the detrital layers is about 20 years (see Figure 3, and discussion in modeling section). Increases in ${ }^{14} \mathrm{C}$ in the $<1.0 \mathrm{~g}$ $\mathrm{cm}^{-3}$ fraction between 1959 and 1990 are less pronounced in the deeper soil horizons, indicating slower decomposition of plant material deeper in the soil. Organic matter with density between 1 and $2 \mathrm{~g}$ $\mathrm{cm}^{-3}$ (Figure 2e) consists of a mixture of charcoal and altered, but still recognizable, plant matter. ${ }^{14} \mathrm{C}$ contents in the pre-bomb soil profile are slightly less than those in the $<1.0 \mathrm{~g} \mathrm{~cm}^{-3}$ fraction, and the increase in ${ }^{14} \mathrm{C}$ between 1959 and 1990 is smaller. Charcoal picked out of the $19901-2 \mathrm{~g} \mathrm{~cm}^{-3}$ density fractions in the $0-23 \mathrm{~cm}$ interval had $\Delta^{14} \mathrm{C}$ of $6 \pm 10$ $\%$. Anecdotal information from the property owner of the site indicates that it was last burned in the late 1950 s or early 1960 s, when this would have been a reasonable value for atmospheric or plant ${ }^{14} \mathrm{C}$. If we assume the total $19901-2 \mathrm{~g} \mathrm{~cm}^{-3}$ fraction $\left(\Delta^{14} \mathrm{C}=\right.$ $+107 \% o$ ) represents a mixture of remnant charcoal $\left({ }^{14} \mathrm{C}\right.$ of $+6 \%$ ) and plant matter similar to that in the $<1 \mathrm{~g} \mathrm{~cm}^{-3}$ fraction $\left(\Delta^{14} \mathrm{C}\right.$ of $\left.+260 \%\right)$, then charcoal makes up roughly $40 \%$ of the carbon in this fraction. The bulk of the soil organic matter in the temperate ecosystem mineral soil is in the dense $\left(\rho>2.0 \mathrm{~g} \mathrm{~cm}^{-}\right.$ 3 ) fraction (Figure 2b). Carbon 14 data for this fraction (Figure 2f) show that the organic carbon associated with the dense fraction contains carbon of greater age than low-density fractions. The $\Delta^{14} \mathrm{C}$ of dense material in the $0-23 \mathrm{~cm}$ layer increases from $-53 \%$ in 1959 to $+70 \%$ in 1990 , a smaller increase than was observed in the low-density fractions. 
A plot of ${ }^{137} \mathrm{Cs}$ activity (measured in the bulk soil; data from R. F. Anderson, Lamont-Doherty Geological Observatory, 1991) is shown for comparison with the ${ }^{14} \mathrm{C}$ data (Figure $2 \mathrm{c}$ ). Measurable quantities of ${ }^{137} \mathrm{Cs}$ are present to only $23 \mathrm{~cm}$ depth in the soil, while bomb ${ }^{14} \mathrm{C}$ is observed deeper than $23 \mathrm{~cm}$, particularly in low-density fractions. This indicates that the source of low-density material deeper than $23 \mathrm{~cm}$ in the soil is from root turnover (or soluble transport) rather than the downward mixing of surface detrital material.

The data in Table 2 show substantial differences in the distribution of carbon and ${ }^{14} \mathrm{C}$ between the tropical and temperate soils. While carbon inventories in the upper $22-23 \mathrm{~cm}$ are similar for both soils, the tropical soil stores more carbon in deeper layers. Low-density material (for the tropical soil, $<1.6 \mathrm{~g} \mathrm{~cm}^{-3}$ ) makes up a only $15 \%$ of the total soil organic matter in the $0-22 \mathrm{~cm}$ layer (compared to $50 \%$ for a similar depth interval in the temperate soil). The Reserva Ducke soil (1986) low-density fraction has $\Delta^{14} \mathrm{C}$ of $+185 \%$, close to the expected 1986 atmospheric value (about $+190 \%$ o [Manning et al., 1989]), and the carbon in surface detrital layers $(+210 \%-220 \%)$. This indicates that turnover rates in the tropical soil may be close to annual in lowdensity fractions. Dense fractions in the tropical soil contained less ${ }^{14} \mathrm{C}$ in the prebomb samples than equivalent depths for the temperate soil. The increase in ${ }^{14} \mathrm{C}$ between 1959 and 1986 , especially in the 0$22 \mathrm{~cm}$ layer, was greater in the tropical soil than in the temperate soil. Thus a larger portion of the tropical soil organic carbon must be in pools which turn over on decadal or shorter time scales. Cesium 137 was only detectable in the detrital layers of the Ducke soil (J. Beer, EAWAG, Switzerland, personal communication, 1990). However, fallout of ${ }^{137} \mathrm{Cs}$ was very low in the southern hemisphere, so it is not a reliable indicator of vertical transport in this soil.

\section{Fractionation by Acid Hydrolysis}

Acid hydrolysis of mineral soil organic matter has been shown by several investigators to leave a residue depleted in ${ }^{14} \mathrm{C}$ [Scharpenseel et al., 1968a; Campbell et al., 1967; Goh et al., 1977; Anderson and Paul, 1984; Trumbore et al., 1989, 1990]. Extraction of the $\rho>2.0 \mathrm{~g} \mathrm{~cm}^{-3}$ fraction with strong acid hydrolyzes proteins, amino sugars, and some carbohydrates [Jawson and Elliott, 1986]. As these are presumably compounds readily utilized by microbes, acid hydrolysis may be expected to remove more labile, rapidly cycling carbon into solution, leaving a more refractory, slower cycling residue [Stout et al., 1981, and references therein]. The acid hydrolysis treatment, however, may also cause functional groups on high molecular weight polymers to be removed or exchanged, thus perhaps adding more ${ }^{14} \mathrm{C}$ rich material to otherwise more refractory carbon, or solubilizing refractory components. To test the efficiency of acid hydrolysis in isolating a "passive" soil organic matter pool, the nonhydrolyzable components of the temperate and tropical prebomb and postbomb soils were compared.

The nonhydrolyzable carbon in the temperate soil contained $15 \%$ to $30 \%$ of the total soil carbon at each depth in the soil profile (Table 2). The residue after hydrolysis in $\mathrm{HCl}$ contained less radiocarbon than the unhydrolyzed dense fraction at all depths in both the 1959 and 1990 temperate soils. Nonhydrolyzable carbon made up a larger portion (40-80\%) of the tropical soil organic carbon. There were, however, no significant differences in the $\Delta^{14} \mathrm{C}$ of the total dense fraction and the residue after $6 \underline{\mathrm{N} \mathrm{HCl}}$ hydrolysis in the 0-22 cm layers of either the 1959 or 1986 Oxisol.

\section{MODELING}

The Mean Residence Time (MRT) of soil carbon is calculated using a decay constant derived from the

Fig. 3. Schematic depiction of the four-component model used to reproduce the ${ }^{14} \mathrm{C}$ contents in prebomb and postbomb soils. The plots are representations of $\Delta^{14} \mathrm{C}$ versus time $\left(1950-2000 \mathrm{~A}\right.$. D.) The atmospheric ${ }^{14} \mathrm{CO}_{2}$ curve (depicted here for the Southern hemisphere [Manning et al., 1990]) is at the far left; annual additions of carbon to each of the four soil components (depicted in the four vertically stacked boxes) are labeled with the ${ }^{14} \mathrm{C}$ content of the atmosphere for that year (northern hemisphere values, used for the Sierra Nevada soil are taken from Levin et al. [1985] and Tans [1981]. Each of the four components is assumed to be homogenous (i.e., represented by a single turnover time for carbon, given as $\tau$ in Figure 3) and at steady state. The turnover time fixes the $1955{ }^{14} \mathrm{C}$ content for each of the four fractions, as well as the increase in ${ }^{14} \mathrm{C}$ during $1955-2000 \mathrm{~A}$. D. The ${ }^{14} \mathrm{C}$ content of the modeled soil organic matter, the sum of the four components weighted by the amount of carbon in each pool (number in the upper right-hand corner of each soil component box), appears in the box at the far right.

To run the model, the amounts of carbon in each of the four components is adjusted until the model reproduces both the observed prebomb and post-bomb ${ }^{14} \mathrm{C}$ contents for the total dense fraction for a given soil and depth interval. The annual fluxes of carbon (numbers over the arrows) are the product of the amount of carbon in each component and $1 / \tau$ As the soil is assumed at steady state, annual inputs $=$ outputs. 


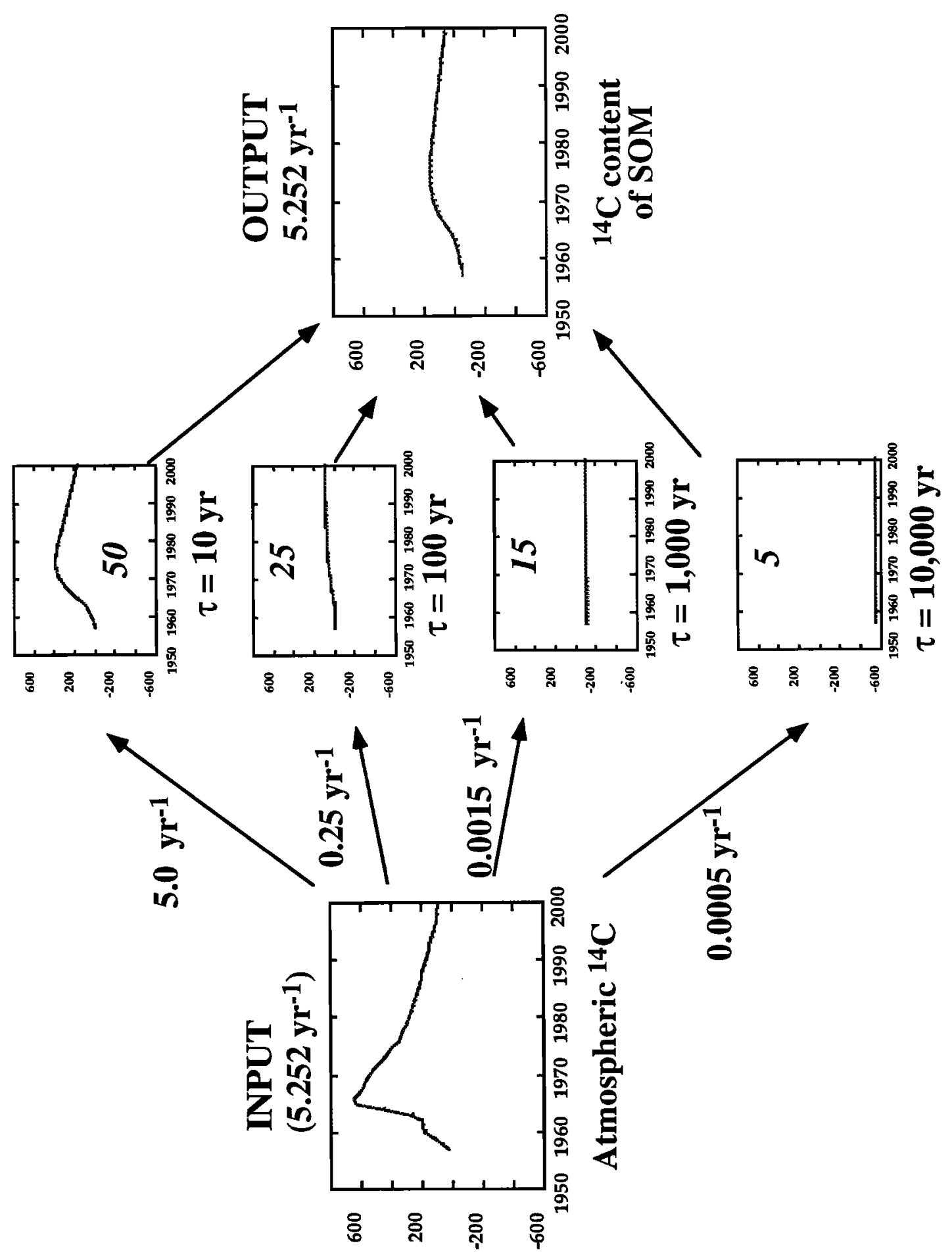


${ }^{14} \mathrm{C}$ content of prebomb organic matter at steady state: $R=\frac{r_{d}}{\left(r_{d}+r_{14}\right)}$, where $R=\Delta^{14} \mathrm{C} / 1000+1$, and $r_{d}$ and $r_{14 C}$ are the decay constants for decomposition (first order) and ${ }^{14} \mathrm{C}$ radioisotope decay [Trumbore et al., 1992]. This relation may be solved for $r_{d}$ when $R$ is measured; the MRT for soil organic matter equals $1 / r_{d}$ [Paul et al., 1964]. MRT's calculated from the ${ }^{14} \mathrm{C}$ contents of the 1959 dense fractions for the temperate and tropical prebomb soils are 470 and 990 years, respectively. The annual inputs (I) required to sustain the carbon inventories observed in these layers, assuming the carbon is homogeneous, with $r_{d}$ equal to the turnover time, would be $0.005 \mathrm{kgC} \mathrm{m}^{-2} \mathrm{yr}^{-1}$ and $0.006 \mathrm{kgC} \mathrm{m}^{-2} \mathrm{yr}^{-1}$ respectively, for the temperate (2.6 $\mathrm{kgC}$ in $0-23 \mathrm{~cm}$ dense fraction) and tropical $(5.7 \mathrm{kgC}$ in $0-22 \mathrm{~cm})$ soils.

The inadequacy of this approach is shown when comparing the observed increase in ${ }^{14} \mathrm{C}$ between 1959 and $1986 / 90$ to that predicted using the values for $I$ and $r_{d}$ derived from the prebomb ${ }^{14} \mathrm{C}$ content of the total dense fraction. In order to reproduce the increases observed in ${ }^{14} \mathrm{C}$ through the $1959-1990$ period, a time-dependent box model (see Figure 3) was used to track the annual additional of new plant matter to the soil (I) and its loss through decay (at rate $r_{d}$ ). The carbon added to the soil annually is assumed to have a ${ }^{14} \mathrm{C} /{ }^{12} \mathrm{C}$ ratio equal to the atmospheric ${ }^{14} \mathrm{CO}_{2}$ content for that year [Levin et al., 1989; Manning et al., 1989]. Using this model and assuming the turnover of soil organic carbon is homogeneous with a decay constant equal to $1 / 470$ years, the predicted increase in ${ }^{14} \mathrm{C}$ for the temperate soil dense fraction is $-53 \%$ in 1959 to $-51 \%$ in 1990. For the Oxisol $\left(r_{d}=1 / 990\right.$ years), the predicted increase is from $-110 \%$ to $-100 \%$. The increases observed in Table 2 are much larger, supporting the concept of organic matter in soils as a mixture of components with different turnover rates.

The effectiveness of the acid hydrolysis fractionation method may be assessed using a similar comparison of prebomb and postbomb radiocarbon data. For example, the predicted increase in ${ }^{14} \mathrm{C}$ for the $6 \underline{\mathrm{N}}$ hydrolysis residue for the $0-22 \mathrm{~cm}$ layer of the temperate soil (Ultisol) should be from -108\%o $\left(1 / r_{d}\right.$ about $\left.1000 \mathrm{yr}\right)$ to $-100 \%$. The observed increase was greater, to $-5 \%$. Hydrolysis of the tropical soil dense fraction in $6 \underline{\mathrm{N}} \mathrm{HCl}$ produced no change in the radiocarbon content of the nonhydrolyzed organic matter. Thus, the residual organic matter after acid hydrolysis still represents a mixture of more rapidly and more slowly cycling material. Although not in itself sufficient to predict the carbon dynamics, the $6 \mathrm{~N} \mathrm{HCl}$ hydrolysis does isolate a more 'passive' fraction in the temperate soil.

As a chemically based fractionation scheme for separating organic matter into labile and refractory pools was unsuccessful, a four-component timedependent box model was used to simulate the increase in ${ }^{14} \mathrm{C}$ between 1959 and 1990 for the dense fractions of the two soils. Figure 3 illustrates the operation of the model. The soil carbon is arbitrarily assumed to consist of four components with MRT's of 1 or $10,100,1000$, and 10,000 years. In reality, the make-up of soil organic matter may be better represented as a continuum, as it is modeled by Ågren and Bosatta [1987] and Balesdent [1987]. However, the simulation as used here is suitable for the task of emphasizing differences between the carbon dynamics in the two soils. The amounts of carbon in each box were adjusted until the model output reproduced (1) the observed inventory of carbon in the total dense fraction, (2) the prebomb (steady state) ${ }^{14} \mathrm{C}$ content of the dense fraction, and (3) the observed increase in ${ }^{14} \mathrm{C}$ in the dense fraction between prebomb and postbomb samples. A family of solutions exists which will reproduce the observations in each case (i.e., a range of allowable amounts of each age fraction may provide the same ${ }^{14} \mathrm{C}$ content in 1959 and 1986 or 1990). Several of these solutions are plotted for the $0-22 \mathrm{~cm}$ layers of the Ultisol (Figure $4 \mathrm{a}$ ) and the Oxisol (Figure 4b). Figures $4 \mathrm{c}$ and $4 \mathrm{~d}$ plot the range of allowed values for each age component. The ranges shown in Figures $4 \mathrm{c}$ and $4 \mathrm{~d}$ may be reduced; if the size of one of the components is fixed, the allowed ranges of the remaining three will be smaller.

Figure 4 shows results only for the dense fraction of the $0-22$ or $0-23 \mathrm{~cm}$ layers of the soils. For the tropical soil (Figure $4 \mathrm{~b}$ ), the $0-22 \mathrm{~cm}$ layer was split into two levels. The 1977 and $1986 \Delta^{14} \mathrm{C}$ in the 0$10 \mathrm{~cm}$ layer organic matter fall directly on the (southern hemisphere) atmospheric ${ }^{14} \mathrm{CO}_{2}$ curve, indicating that the residence time of carbon in this soil layer could be 1 year or less. That result, however, is not consistent with a $1959 \Delta^{14} \mathrm{C}$ value $-110 \%$ for the tropical soil. If the prebomb ${ }^{14} \mathrm{C}$ data from the Curua Una 1959 site may be compared directly with the Reserva Ducke 1986 data, some component of very refractory carbon must be present in the dense fraction. The amount by which the ${ }^{14} \mathrm{C}$ content of the soil is diluted by that refractory component must be compensated for by having some portion of the soil carbon turn over on $10-20$ year time scales (i.e., a component which has ${ }^{14} \mathrm{C}$ values in 1986 which are greater than contemporary atmospheric values). Models which have significant portions of the soil organic matter in the 100 and 1000 year pools cannot reproduce the observations for the Oxisol.

In contrast, the dense fraction of the temperate soil is best modeled using approximately equal portions of the 10,100 , and 1000 year pools. No difference is observed between $0-12$ and $12-23 \mathrm{~cm}$ layers, which may be due to vertical mixing of the soil (evidenced by ${ }^{137} \mathrm{Cs}$ data in Figure $2 \mathrm{f}$ ). In order to 

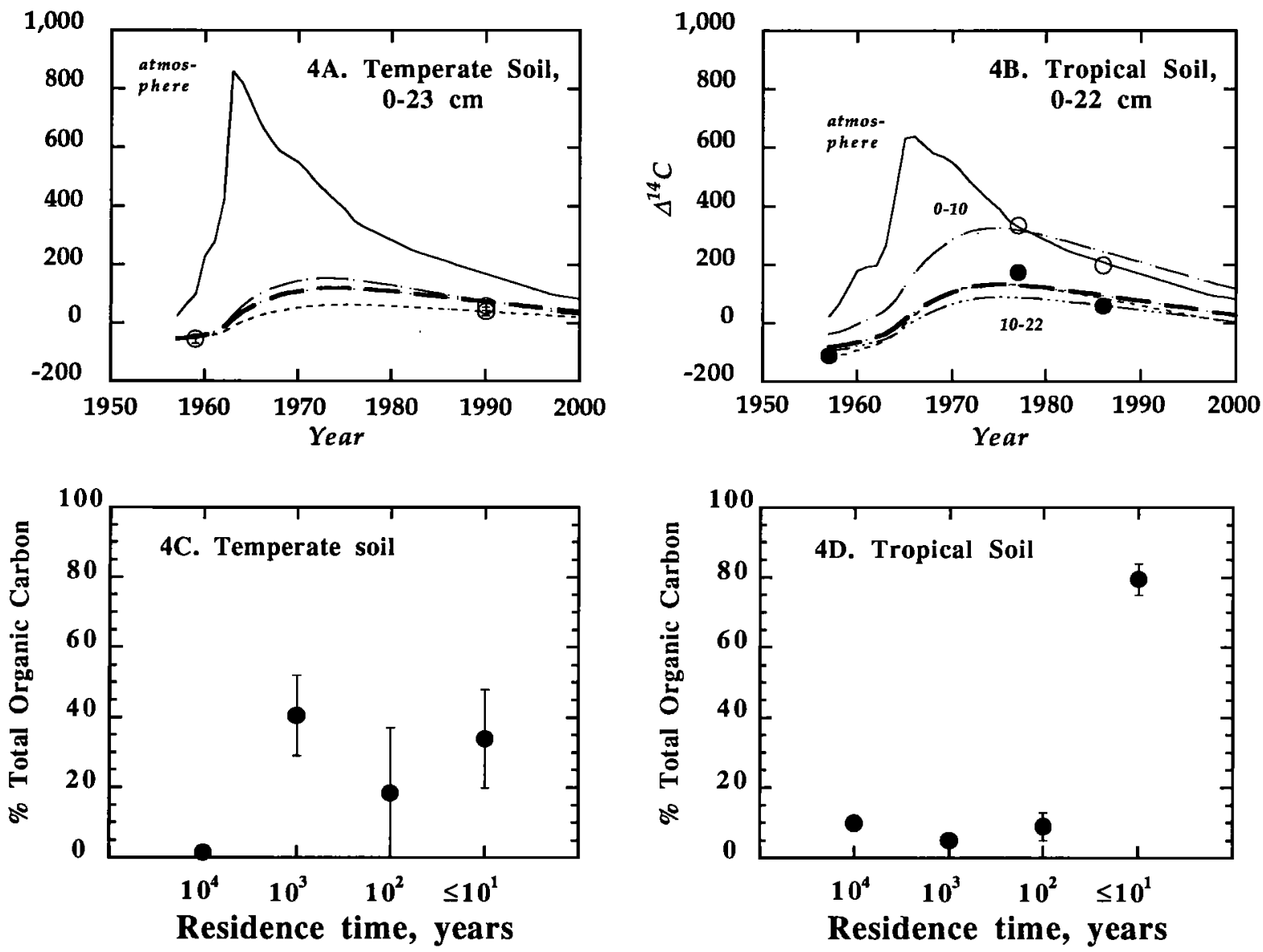

Fig. 4. Typical model results (dashed lines) for the (a) temperate and (b) tropical soils, $0-23$ and $0-22 \mathrm{~cm}$ layers, respectively. Observed ${ }^{14} \mathrm{C}$ data for the total dense fractions of the two soils are also shown (points). The 1959 data for the tropical soils are shown as a range of acceptable values, from $-110 \%$ (observed in the archived soils) to $0 \%$ (the upper limit for late 1950 's ${ }^{14} \mathrm{C}$ ). Data and model results shown here represent soil fractions with density $>2.0 \mathrm{~g} \mathrm{~cm}^{-3}$ only. The partitioning of carbon among the $1-10$ year, 100 year, 1,000 year and 10,000 year pools used for (a) the temperate soil (total of $176 \mathrm{gC} \mathrm{m}^{-2} \mathrm{yr}^{-1}$ ) was: (1) uneven dashed line, $36(20 \%), 60(34 \%)$, $80(46 \%)$ and $0(0 \%)$; (2) uneven dashed line (heavy), $60(34 \%), 56(32 \%), 54(31 \%)$ and $5(3 \%)$; (3) dashed line, $85(48 \%), 0(0 \%), 91(52 \%)$, and $0(0 \%)$. Amounts in the same four pools in (b), the tropical soil $\left(425 \mathrm{gC} \mathrm{m}^{-2} \mathrm{~cm}\right.$ 1 in 0-10 $\mathrm{cm}^{2}$ and $333 \mathrm{gC} \mathrm{m}^{-2} \mathrm{~cm}^{-1}$ in 10-22 $\mathrm{cm}$ ) were: (1) uneven dashed line , $400(94 \%), 0(0 \%), 0(0 \%)$ and 25 (6\%); (2) uneven dashed line (heavy), $155(46 \%), 0(0 \%), 150(45 \%)$ and $28(9 \%)$; (3) dashed and dotted line, $200(60 \%), 50(15 \%), 20(6 \%)$, and $63(19 \%)$. (c) and (d) depict the range of permissible values for the size of each of the components (as per cent of the total dense fraction carbon). These ranges were based on repeated model runs, during which an attempt was made to maximize and minimize the size of each fraction independent of the others.

describe the cycling of organic matter in the $0-23 \mathrm{~cm}$ layer fully, the turnover rate of the low-density organic matter must be determined. The best fit to the 1990 data for low-density material $\left(\rho<2.0 \mathrm{~g} \mathrm{~cm}^{-}\right.$ ${ }^{3}$, exclusive of charcoal) gives a residence time for this fraction of 20 years, assuming this pool is at steady state and may be described using a single decay constant.

An alternative explanation for the observed increases in bomb ${ }^{14} \mathrm{C}$ content in the two soils is that the steady state assumption is not valid, and the soils have been accumulating carbon with time. In order to explain all of the ${ }^{14} \mathrm{C}$ increases observed in the soils (assuming a constant rate of carbon accumulation in the soil since 1959), the total addition of carbon to the Amazon soil (0-22 cm layer only) must increase the carbon inventory in this layer by 80 $90 \%$. The required increase in the temperate soil inventory (to $23 \mathrm{~cm}$ ) is about $30 \%$. The carbon inventory in the 1990 Ultisol profile is $22 \%$ lower 
(to $69 \mathrm{~cm}$ ) than the 1959 archived profile (Table 2), ruling out an accumulation hypothesis for this soil. The decrease in carbon content may reflect the overall uncertainty of carbon inventory determinations, site-to-site differences on meter scales, or anthropogenic influences (cessation of burning; cutting of vegetation). Because the prebomb and postbomb tropical soils come from different sites, the accumulation hypothesis, though producing a measurable effect, cannot be assessed here.

\section{DISCUSSION}

Global carbon cycle models have in the past incorporated soil organic matter (SOM) as a single reservoir with a residence time of about 1000 years (based on the bulk radiocarbon content of soil organic matter in surface soils). More recent models divide SOM into reactive and refractory pools, but little information is available with which to determine the amount of SOM which falls into each category.
The data presented here show that the first approach underestimates the dynamic nature of SOM, especially in tropical regions. In addition, dramatic differences in carbon dynamics are observed in different soil orders, which may need to be incorporated into more complex global carbon cycle models.

Jenkinson et al. [1991, 1992] point out that one of the benefits of a more quantitative understanding of the soil carbon cycle is in improved estimates of the annual input of carbon to soils. The annual input of carbon may be estimated from the amount of carbon in pools with turnover times of $\leq 10,100,1000$, and 10,000 years, and the assumption that the soil carbon is at steady state (see Figure 3 ). At steady state, the annual loss of carbon from the soil equals annual inputs and is the sum of the products of carbon inventory and turnover time for the five SOM pools (including the low density fraction as a separate pool). The calculation of inputs is shown in Table 3. Total fluxes are estimated as 0.22 to 0.45 $\mathrm{kgC} \mathrm{m} \mathrm{yr}^{-1}$ from the Sierra Nevada Ultisol, with

TABLE 3. Calculation of Input Rates for $0-22 \mathrm{~cm}$ and $0-23 \mathrm{~cm}$ Layers of the Temperate and Tropical Soils From Modeled Carbon Abundance and Turnover Rate.

\begin{tabular}{cccc}
\hline Pool & $\begin{array}{c}\text { Decay Rate, } \\
\mathrm{yr}^{-1}\end{array}$ & $\begin{array}{c}\text { Amount, } \\
\mathrm{kg} \mathrm{C} \mathrm{m}^{-2}\end{array}$ & $\begin{array}{c}\text { Flux, } \\
\mathrm{kg} \mathrm{C} \mathrm{m}^{-2} \mathrm{yr}^{-1}\end{array}$ \\
\hline & & TEMPERATE & \\
$\rho<2.0$ & $0.05-0.10$ & 2.6 & $0.13-0.26$ \\
$\rho<2.0$ & & & \\
$1-10$ & $0.1-1.0$ & $0.9-2.2$ & $0-1.3$ \\
100 & 0.01 & $1.4-2.4$ & \\
1,000 & 0.001 & $0-0.2$ & \\
10,000 & 0.0001 & &
\end{tabular}

Total

2.6

$0.22-0.45$

TROPICAL

$\begin{array}{ccc}\rho<2.0 & 1.0 & 1.4 \\ \rho<2.0 & & \\ 1-10 & 0.1-1.0 & 0.9-8.8 \\ 100 & 0.01 & 0.9-2.2 \\ 1,000 & 0.001 & 0.4-1.1 \\ 10,000 & 0.0001 & 0.8-1.4\end{array}$

Total

10.9

$2.6-10.5$

Turnover rates for $\rho<2.0 \mathrm{~g} \mathrm{~cm}^{-3}$ fractions are estimated from ${ }^{14} \mathrm{C}$ data (see text) and from literature values for litter decomposition for both temperate [Jenny et al., 1949] and tropical [Klinge and Rodriguez, 1986] sites. The range in values for each component of the $\rho<2.0 \mathrm{~g}$ $\mathrm{cm}^{-3}$ fraction (from Figures $4 \mathrm{c}$ and $4 \mathrm{~d}$ ) are given in the "Amount" column; individual scenarios like those depicted in Fugres $4 \mathrm{a}$ and $4 \mathrm{~b}$ were used to calculate maximum and minimum fluxes. 
half or more of the annual flux due to turnover of the low-density material in the $0-22 \mathrm{~cm}$ layer (total fluxes include data to $60 \mathrm{~cm}$ ). Fluxes from the tropical soil are larger, $0.5-4.1 \mathrm{kgC} \mathrm{m}^{-2} \mathrm{yr}^{-1}$. The range in values is due to lack of sensitivity in differentiating carbon pools with turnover times of 1 year versus 10 years in the ${ }^{14} \mathrm{C}$ models. The 1977 data from Reserva Ducke suggest that most of the carbon in the $0-10 \mathrm{~cm}$ layer has a residence time of 1 year (see Figure 4b), which would suggest the higher end of the estimated fluxes. However, these samples are purified soil base extracts and thus may overestimate the ${ }^{14} \mathrm{C}$ content of the dense fraction organic matter in 1977 . Figures $4 a$ and $4 b$ show the extreme sensitivity of the modeling exercise to ${ }^{14} \mathrm{C}$ values in soils in the late 1960s and 1970s - archived soils obtained from this period will have the greatest promise of quantifying organic pools in soils which turn over on decadal and shorter time scales. Estimates of annual carbon inputs for both soils have an additional $10-20 \%$ error reflecting the uncertainty in soil carbon inventory.

Table 4 compares inventories and fluxes in the soils to other ecosystem $\mathrm{C}$ fluxes, such as litterfall and soil $\mathrm{CO}_{2}$ respiration, which may help constrain the annual soil carbon fluxes derived from ${ }^{14} \mathrm{C}$ modeling. The data on litterfall and litter turnover are literature values determined in sites close to those from which soil samples were taken (a site with similar elevation and climate, and the same soil as the Sierra Nevada site, and data from a site which is within several $\mathrm{km}$ of the Reserva Ducke; see Table 4 for citations). Comparison of estimated annual C fluxes into and out of soil organic matter are larger than litterfall for both sites. The difference between these two terms is a minimum estimate of the annual contribution of root turnover to SOM; the actual contribution from roots depends on the degree to which organic matter is transferred from the litter layer to the mineral soil. The tropical soil root contributions to soil organic matter estimated in this way are equal to annual litterfall inputs. The temperate soil shows below ground inputs at least four times litterfall; these large values may be due in part to the fact that litterfall estimates were made in an area more than $30 \mathrm{~km}$ away from the soil sampling site.

Soil $\mathrm{CO}_{2}$ flux measurements made during the ABLE II experiments are available from the Reserva Ducke site [Fan et al., 1989]. The measured flux of $\mathrm{CO}_{2}$ was 1.3 to $1.5 \mathrm{kgC} \mathrm{m}^{-2} \mathrm{yr}^{-1}$, with little evidence of seasonal or diel variation. An unknown portion (usually assumed to be around 50\% [Dörr and Münnich, 1989]) of the soil respiration consists of root respired $\mathrm{CO}_{2}$; the rest is from decomposition of soil organic matter and root exudates. The $\mathrm{CO}_{2}$ flux data, which include $\mathrm{CO}_{2}$ from decomposition in litter layers, suggest that the fluxes due to soil organic matter oxidation must be at the lower end of the estimated fluxes given in Table 3 , or closer to

TABLE 4. Comparison of Ecosystem Carbon Fluxes for Temperate and Tropical Sites.

\begin{tabular}{lcc}
\hline & Temperate & Tropical \\
\hline & INVENTORY, $\mathrm{kgC} \mathrm{m}^{-2}$ & \\
Above ground biomass & $3.1 \mathrm{a}$ & $18.9 \mathrm{a}$ \\
Litter & $1.2-6.5 \mathrm{~b}$ & - \\
Soil A $(0-22 \mathrm{~cm})$ & 5.2 & 7.1 \\
Soil B (22-60cm) & 2.3 & 6.9 \\
& FLUX, $\mathrm{kgC} \mathrm{m}^{-2} \mathrm{y}^{-1}$ & \\
NPP C & $0.3-0.5^{\mathrm{a}}$ & $1.0^{\mathrm{a}}$ \\
Litterfall & $0.06^{\mathrm{b}}$ & $0.36-0.40 \mathrm{c}$ \\
direct litter decomposition & $0.01-0.07 \mathrm{~b}$ & - \\
Input soil A & $0.22-0.45^{\mathrm{d}}$ & $0.5-4 . \mathrm{d}^{\mathrm{d}}$ \\
Input soil B & $0.01-0.02 \mathrm{~d}$ & - \\
$\mathrm{CO}_{2}$ flux & - & $1.3-1.5^{\mathrm{e}}$ \\
\hline
\end{tabular}

a Data are from Atjay et al., [1985].

b Data are from Jenny et al., [1949].

c Data are from Klinge and Rodrigues [1968].

d Data are from this study

e Data are from Fan et al., [1990]. 
$0.5 \mathrm{kgC} \mathrm{m}^{-2} \mathrm{yr}^{-1}$. One way to resolve the difference is to measure the ${ }^{14} \mathrm{C}$ content of $\mathrm{CO}_{2}$ respired from the soil. If the SOM is turning over on predominantly annual time scales, the ${ }^{14} \mathrm{C}$ content of respired $\mathrm{CO}_{2}$ will track atmospheric ${ }^{14} \mathrm{CO}_{2}$. SOM dominated by decadal turnover pools should have ${ }^{14} \mathrm{CO}_{2}$ measurably higher than atmospheric values. Depending on the contribution of root respiration to soil respired $\mathrm{CO}_{2}$, this may be best observed though incubation studies or direct field measurements.

\section{CONCLUSIONS}

Radiocarbon is an important and underutilized tool for quantifying the carbon dynamics of soil organic matter and for testing models of soil carbon dynamics. Previous problems which forestalled the use of radiocarbon in soils are now reduced due to the availability of ${ }^{14} \mathrm{C}$ AMS measurements. The comparison of ${ }^{14} \mathrm{C}$ in prebomb and postbomb soil profiles for temperate and tropical ecosystems demonstrates differences in the amount, character, and turnover rate of carbon in organic matter. The tropical forest soil contains more carbon, which turns over more rapidly, than the drier, temperate forest soil. Roughly $50 \%$ of the carbon in the upper $23 \mathrm{~cm}$ of the temperate soil is low density material, while most of the organic matter in the tropical soil is associated with mineral surfaces (dense fraction).

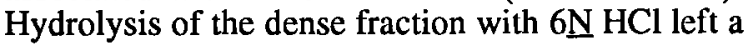
residue depleted in ${ }^{14} \mathrm{C}$ in the temperate, but not the tropical soil.

Modeling of the ${ }^{14} \mathrm{C}$ increase observed in both soils since 1963 demonstrates that the mean residence time derived from bulk soil prebomb ${ }^{14} \mathrm{C}$ is a misleading indicator of the dynamic nature of the soil carbon. The tropical soil contained less ${ }^{14} \mathrm{C}$ in 1959 than the temperate soil, but showed greater increase in ${ }^{14} \mathrm{C}$ since 1963 . Modeling of the acid hydrolysis residue from prebomb and postbomb soils showed that this fraction cannot be used to define the amount of "passive" organic matter, although its ${ }^{14} \mathrm{C}$ content may represent a reasonable turnover rate for passive pools. Annual rates of carbon input to soils, derived from modeling the ${ }^{14} \mathrm{C}$ increase in density-separated soil organic matter, show that below ground inputs of carbon are at least as important as litterfall in adding carbon to the A horizons of both soils.

The ability to differentiate ${ }^{14} \mathrm{C}$ increases over the past 30 years due to carbon accumulation from those due to carbon exchange with atmospheric $\mathrm{CO}_{2}$ in steady state soils will be important if ${ }^{14} \mathrm{C}$ isotopes can be used to determine whether soils are sequestering carbon at an increased rate due to biosphere fertilization. At present, ${ }^{14} \mathrm{C}$ data will be a necessary test of any accumulation hypothesis. Unfortunately, unless the soil carbon dynamics are well understood under steady state conditions, ${ }^{14} \mathrm{C}$ data alone are not an independent measure of carbon sequestration rates in soils.
Acknowledgments. I would like to thank the AMS laboratories in Zürich (PSI/ETH) and at LLNL, where this work was conducted. My salary was paid in Switzerland by a postdoc with W. S. Broecker (Lamont-Doherty), and in Livermore by a post-doctoral appointment at LLNL. Discussions with W. S. Broecker, J. Harden, O. Chadwick and $\mathrm{R}$. Amundson were helpful to the completion of this work. R. F. Anderson at Lamont-Doherty Geological Observatory and J. Beer at EAWAG kindly provided ${ }^{137} \mathrm{Cs}$ analyses. Benny Brasher at the U.S. Soil Survey Investigations Laboratory kindly provided access to archived soils. I am indebted to three anonymous reviewers for helpful comments. The writing of this paper was performed under the auspices of the U.S. Department of Energy by the Lawrence Livermore National Laboratory under contract number W-7405-Eng-48.

\section{REFERENCES}

Ågren, G. I., and E. Bosatta, Theoretical analysis of the long-term dynamics of carbon and nitrogen in soils, Ecology, 68, 1181 - 1189, 1987.

Aravena, R., S. L. Schiff, S. E. Trumbore, and R. Elgood, Evaluating dissolved inorganic carbon cycling in a forested lake watershed using carbon isotopes. Radiocarbon, 34, 363-345, 1992.

Atjay, G. L., P Ketner and P. Duvigneaud, Terrestrial primary production and phytomass, in, The Global Carbon Cycle, SCOPE 13, edited by B. Bolin, E. T. Degens, S. Kempe and P. Ketner,pp. 129-182, John Wiley, New York, 1979.

Anderson, D. W., and E. A. Paul, Organomineral complexes and their study by radiocarbon dating, Soil Sci. Soc. Am. J., 48, 298 - 301, 1984.

Amundson, R. G., and E. A. Davidson, Carbon dioxide and nitrogenous gases in the soil atmosphere, J.of Geochem.Explor. 38, 13 - 41, 1990.

Balesdent, J., The turnover of soil organic fractions estimated by radiocarbon dating,Sci.Total Environ. 62, 405 - 408, 1987.

Brady, N. C., The Nature and Properties of Soils, pp. 415-473, Macmillan, New York, 1984.

Buchanan, D. L., and B. J. Corcoran, Sealed tube combustions for the determination of carbon-13 and total carbon, Anal. Chem. 31, 1635, 1959.

Campbell, C. A., E. A. Paul, D. A. Rennie, and K.J. McCallum, Applicability of the carbondating method of analysis to soil humus studies, Soil Sci. 104, 217-224, 1967.

Davis, J. C., et al., LLNL/UC AMS facility and research program: Proc. 5th International Conference on Accelerator Mass Spectrometry, Paris, Nuc. Instr. Methods, B52, 269-272, 1990.

Dörr, H., and K. O. Münnich, Downward transport of soil organic matter and its influence on traceelement transport $\left({ }^{210} \mathrm{~Pb},{ }^{137} \mathrm{Cs}\right)$ in the soil, Radiocarbon,31, 655-663, 1989. 
Emanuel, W. R., H. H. Schugart, and M. P. Stevenson, Climate change and the broad-scale distribution of terrestrial ecosystem complexes, Clim.Change, 7, 29-43, 1985.

Fan, S-M, S. C. Wofsy, P. S. Bakwin, D. J. Jacob, and D. R. Fitzjarrald, Atmospherebiosphere exchange of $\mathrm{CO}_{2}$ and $\mathrm{O}_{3}$ in the central Amazon forest, J. Geophys. Res., 95, 16,851 $16,864,1990$.

Goh, K. M., T. A. Rafter, J. D. Stout, and T. W. Walker, The accumulation of soil organic matter and its carbon isotope content in a chronosequence of soils developed on aeolian sand in New Zealand,N. Z. J. Soil Sci. , 27, 89$100,1976$.

Goh, K. M., J. D. Stout, and T. A. Rafter, Radiocarbon enrichment of soil organic matter fractions in New Zealand soils,Soil Sci., 123, 385-391, 1977.

Goh, K. M., J. D. Stout, and B. J. O'Brien, The significance of fractionation dating in dating the age and turnover of soil organic matter, N. Z. J. Soil Sci., 35, 69-72, 1984.

Graustein, W. C., and K. K. Turekian, ${ }^{210} \mathrm{~Pb}$ and ${ }^{137} \mathrm{Cs}$ in air and soils measure the rate and vertical profile of aerosol scavenging, J. Geophys. Res., $91,14,355$ - 14,366, 1986.

Harkness, D. D., A. F. Harrison, and P. J. Bacon, The temporal distribution of 'bomb' ${ }^{14} \mathrm{C}$ in a forest soil, Radiocarbon, 28, 328-337, 1986.

Harriss. R. C., et al., The Amazon Boundary Layer Experiment: Wet season 1987,J. Geophys. Res., $95,16,721$ - 16, 737, 1990.

Intergovernmental Panel on Climate Change, Climate Change: The IPCC Scientific Assessment, University Press, Cambridge, 1990.

Irion, G., Clay minerals of Amazonian soils, in,The Amazon, edited by H. Siolo, pp. 537-580, W. Junk, Dordrecht, 1984.

Jawson, M. D., and L. F. Elliott, Carbon and nitrogen transformations during wheat straw and root decomposition, Soil Biol. Biochem., 18, 15$22,1986$.

Jenkinson, D. J., and J. H. Raynor, The turnover of soil organic matter in some of the Rothamsted classical experiments,Soil Sci.,123, 298 - 305, 1977.

Jenkinson, D. J., D. E. Adams, and A. Wild, Model estimates of $\mathrm{CO}_{2}$ emissions from soil in response to global warming, Nature, 351, 304306, 1991.

Jenkinson, D. S., D. D. Harkness, E. D. Vance, D. E. Adams, and A. F. Harrison, Calculating net primary production and annual input of organic matter to soil from the amount and radiogenic content of soil organic matter, Soil Biol. Biochem., 24, 295 - 308, 1992.

Jenny, H., S. P Gessel, and F. T. Bingham, Comparative study of decomposition of organic matter in temperate and tropical regions, Soil Sci., 67,419 - 432, 1949.
Jenny, H., Causes of high nitrogen and organic matter content in temperate and tropical soils, Soil Science, 69, 63-69, 1950.

Klinge, H., and W. A. Rodriguez, Litter production in an area of Amazonian terra firme forest, Part 1, Litter-fall, organic carbon and total nitrogen contents of litter, Amazoniana, 1, 287 - 302, 1968.

Leenheer, J. A., Origin and nature of humic substances in the waters of the Amazon River basin, Acta Amazon., 10, 513-526, 1980.

Levin, I., B. Kromer, H. Schoch-Fischer, M. Bruns, M. Münnich, D. Berdau, J. C. Vogel, and K. O. Münnich, 25 years of tropospheric ${ }^{14} \mathrm{C}$ observations in central Europe, Radiocarbon, 27, 1-19, 1985.

Manning, M. R., D. C. Lowe, W. H. Melhuish, R. J. Sparks, G. Wallace, C. A. M. Brenninkmeijer, and $R$. C. McGill, The use of radiocarbon measurements in atmospheric studies, Radiocarbon, 32, 37 - 58, 1990.

Martel, Y. A., and E. A. Paul, The use of radiocarbon dating of organic matter in the study of soil genesis, Soil Sci. Soc. Am. Proc., 38, 501-506, 1974.

Monaghan, M. C., ${ }^{10} \mathrm{Be}$ in the atmosphere and soils, Ph.D. thesis, Yale Univ., New Haven, Conn., 1984.

O'Brien, B. J., Soil organic carbon fluxes and turnover rates estimated from radiocarbon enrichments, Soil Biol. Biochem., 16, 155-120, 1984.

O'Brien, B. J., The use of natural anthropogenic ${ }^{14} \mathrm{C}$ to investigate the dynamics of soil organic carbon, Radiocarbon, 28, 358-362, 1986.

O'Brien, B. J., and J. D. Stout, Movement and turnover of soil organic matter as indicated by carbon isotopic measurements, Soil Biol. Biochem., 10, 309-317, 1978.

Parton, W. J., D. S. Schimel, C. V. Cole and D. S. Ojima, Analysis of factors controlling soil organic matter levels in Great Plains grasslands, Soil Sci. Soc. Am.J., 51, 1173-1179, 1987.

Paul, E. A., C. A. Campbell, D. A. Rennie and K. $\mathrm{J}$. McCallum, Investigations of the dynamics of soil humus utilizing carbon dating techniques, in, Transactions of the 8th International Soil Science Society (Bucharest, Romania), 3, 201-208, Internaltional Soil Science Society, Vienna, 1964.

Post, W. M., W. P. Emanuel, P. J. Zinke, and A. G. Stangenberger, Soil carbon pools and world life zones, Nature, 298, 156-159, 1982.

Prentice, K. C., and I. Y. Fung, The sensitivity of terrestrial carbon storage to climate change, Nature, 346, 48 - 51, 1990.

Scharpenseel, H. W., C. Ronzani, and F. Pietig, Comparative age determinations on different humic-matter fractions, in, Proceedings of a Symposium on the use of isotopes and radiation in soil organic matter studies, July, 1968, pp. 67- 
74, International Atomic Energy Commission, Vienna, 1968a.

Scharpenseel, H. W., M. A. Tamers, and F. Pietig, Altersbestimmung von Boden durch die Radiokohlenstoffdatierungsmethode, Z. Pflanz. Bodenk., 119, 34-52, $1968 \mathrm{~b}$.

Scharpenseel, H. W., H. Schiffmann, and B. Hintze, Hamburg University radiocarbon dates III, Radiocarbon , 26, 196-205, 1984.

Scharpenseel, H. W., P. Becker-Heidmann, H. U. Neue and K. Tsutsuki, Bomb-carbon, ${ }^{14} \mathrm{C}$ dating and ${ }^{13} \mathrm{C}$ measurements as tracers of organic matter dynamics as well as of morphogenic and turbation processes, Sci.Total Environ., 81/82, 99-110, 1989.

Schlesinger, W. H., Carbon balance in terrestrial detritus. Annu. Rev. Ecol. Syst., 8, 51-81, 1977.

Schlesinger, W. H., Evidence from chronosequence studies for a low carbon-storage potential of soils, Nature, 348, 232-234, 1990.

Soil Survey Investigations Report (SSIR), Soil Survey Laboratory data and descriptions for some soils of Iowa, Rep. 3 (Iowa), Soil Conserv. Serv., U.S. Dep. of Agri., Washington, D. C., 1970.

SSIR, Soil Survey Laboratory data and descriptions for some soils of California, Rep. 24 (California), Soil Conserv. Serv., U.S. Dep. of Agri., Washington, D. C., 1973.

Sollins, P., G. Spycher, and C. Topik, Processes of soil organic matter accretion at a mudflow chronosequence, Mt. Shasta, California, Ecology, 64, 1,273-1,282, 1983.

Sombroek, W. G., Amazon Soils, Centre for Agricultural Publication and Documentation, Wageningen, The Netherlands, 1966.

Spycher, G., P. Sollins, and S. Rose, Carbon and nitrogen in the light fraction of a forest soil: Vertical distribution and seasonal patterns, Soil Sci., 135, 79-87, 1983.

Stevenson, F. J., Humus Chemistry, John Wiley, New York, 1982.

Stevenson, F. J., and E. T. Elliott, Methodologies for assessing the quantity and quality of soil organic matter, in, Dynamics of Soil Organic Matter in Tropical Ecosystems, edited by D. C. Coleman, J. M. Oades, and G. Uehara, pp. 173242, University of Hawaii Press, Honolulu, 1990.

Stout, J. D., K. M. Goh, and T. A. Rafter, Chemistry and turnover of natually occurring resistant organic compounds in soil, edited by $\mathbf{E}$.
A. Paul, and J. N. Ladd, Soil Biochem., 5, 173, 1981.

Stuiver, M., and H. Polach, Reporting of ${ }^{14} \mathrm{C}$ data, Radiocarbon, 19, 355-363, 1977.

Suter, M., et al., Precision measurements of ${ }^{14} \mathrm{C}$ in AMS - some results and prospects, Nucl. Instr. Methods, B5, 117-122, 1984.

Tans, P., A compilation of bomb ${ }^{14} \mathrm{C}$ for use in global carbon cycle calculations, in, Carbon Cycle Modeling, SCOPE 16, edited by B. Bolin, pp. 131-157, John Wiley, New York, 1981.

Tans, P., I. Y. Fung, and T. Takahashi, Observational constraints on the atmospheric $\mathrm{CO}_{2}$ budget, Science, 247, 1431-1438, 1990.

Trumbore, S. E., Carbon cycling and gas exchange in soils, Ph.D. thesis, Columbia Univ., New York, New York, 1988.

Trumbore, S. E., J. S. Vogel, and J. R. Southon, AMS ${ }^{14} \mathrm{C}$ measurements of fractionated soil organic matter: an approach to deciphering the soi carbon cycle, Radiocarbon, 31, 644-654, 1989.

Trumbore, S. E., G. Bonani, and W. Wölfli, The rates of carbon cycling in several soils from AMS ${ }^{14} \mathrm{C}$ measurements of fractionated soil organic matter, in, Soils and the Greenhouse Effect, edited by A. F. Bouwman, pp. 405-414, John Wiley, New York, 1990.

Van Breemen, N., and T. C. J. Feijtel, Soil processes and properties involved in the produciton of Greenhouse Gases, with special relevance to soil taxonomic systems, in, Soils and the Greenhouse Effect, edited by A. F. Bouwman, pp. 405-414, John Wiley, New York, 1990.

Vogel, J. S., D. E. Nelson, and J. R. Southon, ${ }^{14} \mathrm{C}$ background levels in an accelerator mass spectrometry system, Radiocarbon, 29, 323-333, 1987.

Zinke, P J Stangenberger, A G, Post, W M, Emanual, W $R$ and Olson, J S, Worldwide organic soil carbon and nitrogen data, Environ. Sci. Div. Publ. 2212, Oak Ridge Nat. Lab., 141 pp., Oak Ridge, Tenn., 1984.

S. E. Trumbore, Center for Accelerator Mass Spectrometry, Lawrence Livermore National Laboratory, Livermore, CA 94550.

(Received November 16, 1992; revised February 15, 1993; accepted February 25, 1993.) 